\title{
Linear lichen sclerosus of the face
}

\section{Niraj Parajuli', Pratima Poudel ${ }^{2}$, Sumida Tiwari ${ }^{3}$, Anupama Karki ${ }^{1}$}

\author{
${ }^{1}$ Department of Dermatology, National Academy of Medical Sciences, Bir Hospital, Kathmandu, Nepal, ${ }^{2}$ Department of \\ Dermatology, Kanti Children's Hospital, Kathmandu, Nepal, ${ }^{3}$ Department of Pathology, National Academy of Medical \\ Sciences, Bir Hospital, Kathmandu, Nepal
}

Corresponding author: Dr. Niraj Parajuli, E-mail: nirpana@hotmail.com

\begin{abstract}
Lichen sclerosus (LS) is a chronic inflammatory disease of unknown origin that mostly affects women in their fifties and sixties and that commonly affects the anogenital region but may rarely present itself in extragenital areas. The most common locations of extragenital LS includes the neck, shoulder, and upper trunk. LS of the anogenital region is associated with an increased incidence of malignancies, which is not the case with extragenital LS. Herein, we report the case of a married 45-year-old female who presented herself to us with LS of the face of a linear pattern. Facial LS is quite rare and, even more so, in linear plaque patterns.
\end{abstract}

Key words: Extragenital; Facial; Follicular plugging; Lichen sclerosus; Linear

\section{INTRODUCTION}

Lichen sclerosus (LS) is a chronic inflammatory disease of unknown origin that mostly affects women in their fifties and sixties, although it may occur in men and children [1]. LS commonly affects the anogenital region, quite rarely presenting itself as an isolated extragenital lesion [2]. Extragenital lichen sclerosus (ELS) is most common on the neck, shoulders, and upper trunk. However, a linear distribution of ELS lesions is rare [3].

The etiology of LS remains unclear but strong evidence indicates that an autoimmune mechanism may play a significant role. LS is also characterized by genetic susceptibility [2]. LS of the anogenital region is associated with an increased incidence of malignancies, especially vulvar squamous cell carcinomas. The lifetime risk of developing this type of carcinoma is approx. 5\%. However, no such risk is noted in ELS and LS in children [4].

The mainstay of treatment is still potent and ultrapotent topical corticosteroids. Other modalities include topical calcineurin inhibitors, topical and systemic retinoids, phototherapy, and photodynamic therapy [2].
Herein, we report a case of lichen sclerosus of the face that presented itself in a linear pattern, which has not been reported, to date, in Nepal.

\section{CASE REPORT}

A 45-year-old Nepali female presented herself with a single mildly pruritic linear plaque gradually increasing over the right temporal face for the last six months. The atrophic plaque extended from the right temple up to the angle of the mandible. Neither scaling nor surrounding hyperpigmentation was noted. There was no history of chronic illness.

On physical examination, a linear slightly atrophic plaque with prominent follicular plugging was noted along the right temporal-mandibular region. Cicatricial alopecia was also noted over the lesional skin of the temple (Fig. 1).

A histopathological examination of the skin from the center of the lesion revealed thinning of the epidermis with a lamellated keratin layer with areas of follicular plugging. The basement membrane was delicate. The dermis was relatively thickened. The focal areas

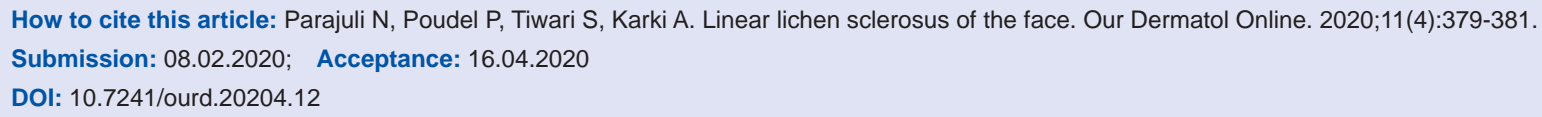


in the lower dermis showed lymphocytic aggregates adjacent to hair follicles. Sparse hair follicles and a few horn cysts were seen in the upper dermis (Fig. 2). A diagnosis of lichen sclerosus was reached and the patient was started on a potent topical corticosteroid. A slight improvement was noted after two weeks. The patient was advised to attend regular follow-ups, but failed to do so.

\section{DISCUSSION}

While extragenital LS is not an uncommon entity, facial involvement is rare. There have been only a handful of cases of LS of the face mentioned in the literature [5-10]. Exclusive extragenital LS was reported to occur in up to $15 \%$ of patients [5].

The cause of LS is still largely unknown, but recent evidence points toward autoimmunity and genetic predisposition [2]. There is a slight increase in the risk of malignant transformation of genital LS, which is not

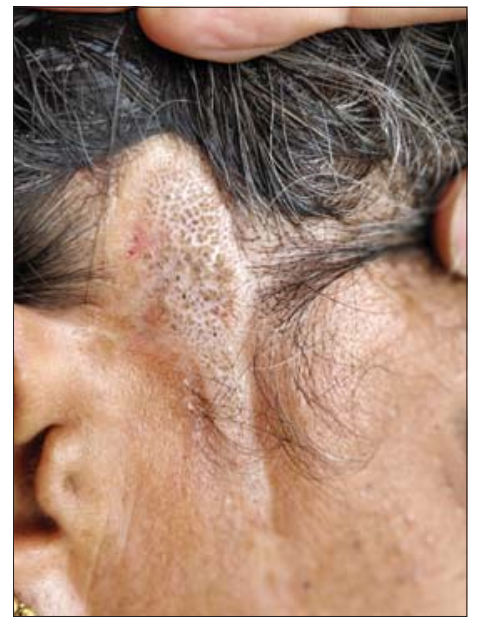

Figure 1: A linear plaque with prominent follicular plugging at the right temporal region of the face.

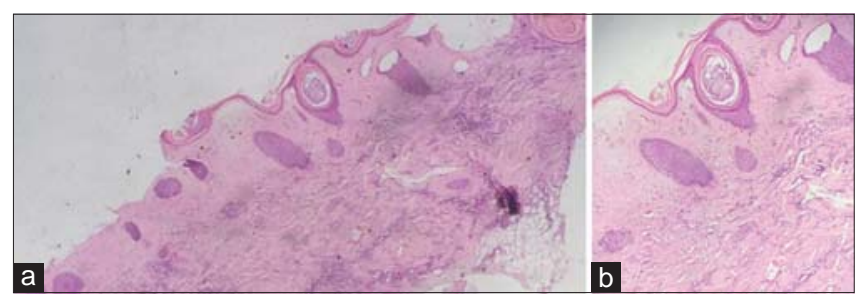

Figure 2: (a) A histopathological examination of the skin showing prominent lamellated keratin with areas of prominent follicular plugging (H\&E, 40x). (b) A thinned epidermis with hyperkeratosis at higher magnification; the dermoepidermal junction showing sparse lymphocytic infiltration and a homogenized band of dense collagen in the upper dermis; focal areas in the lower dermis showing lymphocytic aggregates adjacent to hair follicles (H\&E, 100x). the case with children as well as with ELS [4]. Although the exact prevalence of $\mathrm{LS}$ is unknown, it is more common in females, with a male-to-female ratio of 1:6, and may occur at any age [6]. Clinically, LS presents itself as macules, papules, or shiny white plaques with follicular corneal plugs [11]. The area may evolve into a dry, hypopigmented, or sclerotic, and later atrophic lesion. The resulting crinkling or cellophane paper-type appearance is pathognomonic of lichen sclerosus [2].

$\mathrm{LS}$ is mostly a clinical diagnosis. Because it may sometimes be confused with morphea, a histopathological examination is important to differentiate the two. LS has a characteristic histological pattern. The epidermal changes include hyperkeratosis, follicular occlusion, thinning of the epidermis, and vascular alterations in the basal layer. Subepidermal edema with homogenization of collagen, sclerosis, and dilation of small vessels with hemorrhage are also noted. A diffuse perivascular infiltrate of lymphocytes appearing under the edema may occur in the middle third of the dermis [12].

First-line treatment of LSA includes potent and ultrapotent topical corticosteroids. Second-line therapies include topical calcineurin inhibitors. Systemic agents include oral steroids, retinoids, and cyclosporine, and may be of some use [13].

\section{CONCLUSION}

This is the first case of linear ELS reported in Nepal. LS may be confused with morphea or discoid lupus due to the presence of follicular plugging and atrophy. A proper examination and a biopsy help to differentiate between these conditions.

\section{Consent}

The examination of the patient was conducted according to the principles of the Declaration of Helsinki.

The authors certify that they have obtained all appropriate patient consent forms, in which the patients gave their consent for images and other clinical information to be included in the journal. The patients understand that their names and initials will not be published and due effort will be made to conceal their identity, but that anonymity cannot be guaranteed.

\section{REFERENCES}

1. Louvain D, Moura Jacques C, Fernandes Ferreira A, Hoehl Carneiro L, Quintela L, Cuzzi T, et al. Lichen sclerosus in the oral 


\section{www.odermatol.com}

mucosa: a rare form of presentation. Acta Dermatovenerol Croat ADC. 2012;20:43-7.

2. Fistarol SK, Itin PH. Diagnosis and treatment of lichen sclerosus: an update. Am J Clin Dermatol. 2013;14:27-47.

3. Ganesan L, Parmar H, Das JK, Gangopadhyay A. Extragenital lichen sclerosus et atrophicus. Indian J Dermatol. 2015;60:420.

4. Jędrowiak A, Kobusiewicz A, Trznadel-Grodzka E, Kaszuba A. Dermoscopic findings in extragenital lichen sclerosus. Our Dermatol Online. 2018;9:197-9.

5. Rosenthal IM, Taube JM, Nelson DL, Erdag G. A case of infraorbital lichen sclerosus. Dermatol Online J. 2013;19:20021.

6. Diwan NG, Nair PA. Extragenital lichen sclerosus et atrophicus along the lines of Blaschko. Indian Dermatol Online J. 2015;6:342-4.

7. Coelho WS, Diniz LM, Filho S, De JB. Lichen sclerosus et atrophicus: report of two cases with atypical presentations. An Bras Dermatol. 2006;81:S297-300.

8. Yu L, Li Z, Feng S. Lichen sclerosus of face: A case report and review of literature. Indian J Dermatol. 2016;61:120.

9. Kaur S, Thami GP, Kanwar AJ, Mohan H. Linear oro-facial lichen sclerosus. Clin Exp Dermatol. 2002;27:467-70.
10. Kim CR, Jung KD, Kim H, Jung M, Byun JY, Lee D-Y, et al. Linear Lichen Sclerosus along the Blaschko's Line of the Face. Ann Dermatol. 2011;23:222-4.

11. Viana F de O, Cavaleiro LH dos S, Unger DAA, Miranda MFR de, Brito AC de. Acral lichen sclerosus et atrophicus: case report. An Bras Dermatol. 2011;86:82-4.

12. Meffert J, Zeichner JA, Talavera F, Chan EF, Quirk CM, James WD. Lichen sclerosus et atrophicus. In: Elder D, Elenitsas R, Jaworsky C, Johnson B Jr, editors. Lever's Histopathology of the Skin. Philadelphia: Lippincott-Raven Publishers; 1997. pp. 280-3.

13. Patel B, Gupta R, Vora VR. Extra Genital Lichen Sclerosus et Atrophicus With Cutaneous Distribution and Morphology Simulating Lichen Planus. Indian J Dermatol. 2015;60:105.

Copyright by Niraj Parajuli, et al. This is an open access article distributed under the terms of the Creative Commons Attribution License, which permits unrestricted use, distribution, and reproduction in any medium, provided the original author and source are credited.

Source of Support: Nil, Conflict of Interest: None declared. 